\title{
Conjunctival Dysplasia and Atypical Secondary Acquired Melanosis in Xeroderma Pigmentosum
}

\author{
Lim EWL ${ }^{1}, \operatorname{Lim} L^{2}$, Jajeh $I^{3^{*}}$ and Jayasinghe $L^{2,4}$ \\ ${ }^{1}$ Yong Loo Lin School of Medicine, National University of Singapore, 1E Kent Ridge Road, Singapore \\ ${ }^{2}$ Corneal and External Eye Disease Service, Singapore National Eye Centre, Singapore \\ ${ }^{3}$ Histopathology, Pathology Department, Singapore General Hospital, Singapore \\ ${ }^{4}$ Department of Ophthalmology, Teaching Hospital Kandy, Sri Lanka
}

*Corresponding author: Issam Al Jajeh Pathology, Mailing address: 20 College Road, Academia, Level 10, 169856, Singapore, Tel: 6-5 6321 4875; Fax: +65 6222 6826; E-mail: issam.al.jajeh@sgh.com.sg

Received date: February 15, 2016; Accepted date: April 15, 2016; Published date: April 25, 2016

Copyright: $\odot 2016$ Lim EWL, et al. This is an open-access article distributed under the terms of the Creative Commons Attribution License, which permits unrestricted use, distribution, and reproduction in any medium, provided the original author and source are credited.

\begin{abstract}
Xeroderma pigmentosum $(\mathrm{XP})$ is a rare genetic disease associated with hypersensitivity to ultraviolet radiation resulting in cutaneous, ocular and neurological abnormalities. Ocular involvement typically includes photophobia, keratitis, corneal opacity and atrophy of the eyelids, along with carcinomas and melanomas. We report a rare case of conjunctival dysplasia and atypical secondary acquired melanosis in a patient with XP.

A 9 year old Indian boy with a history of XP presented with conjunctival lesions over the course of one year. The ocular involvement manifested as conjunctival actinic keratosis/epithelial dysplasia and atypical secondary acquired melanosis. To the best of our knowledge, atypical secondary acquired melanosis has not previously been reported in association with XP in the literature.

We present our clinical and histopathological findings of conjunctival dysplasia and atypical secondary acquired melanosis in this patient. Although acquired melanosis with atypia is known to occur and is often reported as a cutaneous manifestation of XP, it is rarely reported as a conjunctival manifestation in XP. It is possible that the early acquired melanosis is overshadowed by more visible conjunctival intraepithelial neoplasia (CIN) lesions.
\end{abstract}

Keywords: Actinic keratosis; Atypical secondary acquired melanosis; Conjunctival intraepithelial neoplasia (CIN); Conjunctival neoplasia; Xeroderma pigmentosum (XP)

\section{Introduction}

Xeroderma pigmentosum (XP) is a rare autosomal recessive disease with a low prevalence of 1 in 250,000 worldwide. The disease is caused by defective DNA repair, leading to a clinical and cellular hypersensitivity to ultraviolet radiation $[1,2]$. XP presents with the onset of cutaneous, ocular and neurodegenerative abnormalities. Cutaneous abnormalities include skin sensitivity, squamous cell carcinomas, basal cell carcinomas and malignant melanomas [3]. Ocular abnormalities occur mainly in the conjunctiva, cornea and eyelid, tissues which receive more UV exposure. Ocular involvement includes photophobia, keratitis, corneal opacity and atrophy of the eyelids, along with carcinomas and melanomas [1]. According to a review by Kraemer et al., [3] ocular abnormalities occur in $40 \%$ of patients with XP and ocular neoplasm occurs in $11 \%$ of them. Conjunctival ocular neoplasms are rare, only occurring in $2 \%$ of patients with XP [3]. Some individuals also exhibit neurological manifestations, such as acquired microcephaly and reduced deep tendon stretch reflexes. Due to skin cancers, internal cancers and neurodegeneration, patients with XP have a short life expectancy of around 37 years [1]. The clinical and histopathologic findings of bilateral conjunctival preneoplasia and atypical secondary acquired melanosis in a patient with XP are presented in this report. In a case report by Paridaens et al. [4], primary acquired melanosis with atypia was discovered in a patient with XP. However, to the best of our knowledge, atypical secondary acquired melanosis has not been previously reported in XP.

\section{Case Presentation}

A 9 year old Indian boy with history of XP has been under follow up at the Singapore National Eye Centre since 2005. On general examination, he had widespread freckles on the face, backs of the hands, arms and neck. Best corrected visual acuity was 6/6 in both eyes. His parents and elder sister were unaffected. He had no significant ocular involvement except mild photophobia and conjunctival injection until October 2011 when he presented with a right nasal conjunctival nodule with pigmentation noted inferior to the nodule (Figure 1A and 1B). Excision biopsy, cryotherapy and conjunctival graft with fibrin glue were performed.

Histopathological examination showed actinic keratosis (Figure 1C) and atypical secondary acquired melanosis (Figure 2A-2C). Postoperative recovery was uneventful.

Nine months later in July 2012, another conjunctival nodule (nonpigmented) in the left temporal limbus was observed. A similar operation was performed and histology also showed actinic keratosis. Post-operative recovery was uneventful.

Ten months later in May 2013, a third lesion appeared in the right temporal conjunctiva but this time, the patient's parents requested a 
Citation: Lim EWL, Lim L, Jajeh IA , Jayasinghe LS (2016) Conjunctival Dysplasia and Atypical Secondary Acquired Melanosis in Xeroderma Pigmentosum. J Cytol Histol 7: 1000405. doi:10.4172/2157-7099.1000405

Page 2 of 3

delay in the biopsy. The biopsy was only performed seven months after the discovery of the lesion, when the conjunctival nodule increased in size. Apart from excision biopsy, cryotherapy and conjunctival grafting with fibrin glue were also performed, as for the previous two lesions. The biopsy showed focal moderate dysplasia, equivalent to conjunctival intraepithelial neoplasia 2, (CIN2). The margins were free of dysplasia (Figure 3).

All three lesions arose from different regions in both the patient's eyes and no recurrence at the primary site was observed to date.
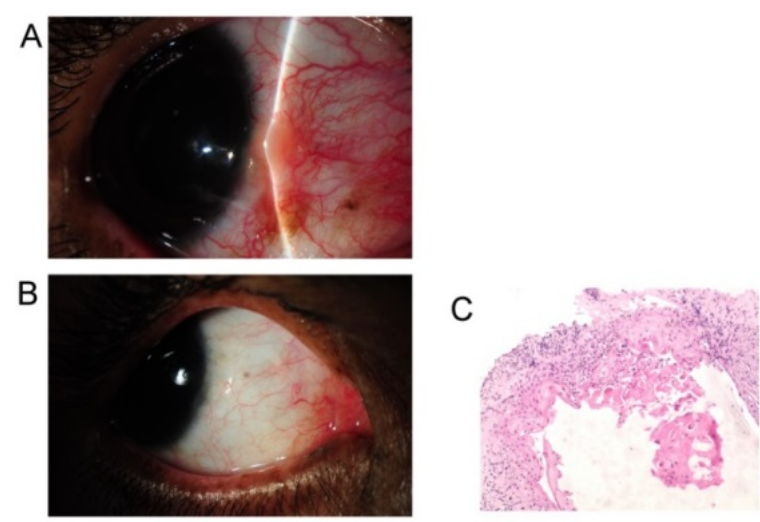

Figure 1: First conjunctival nodule at the right nasal limbus A) Right nasal limbus showing a vascularised conjunctival nodule before biopsy B) Right nasal limbus 9 months after excision biopsy, cryotherapy, conjunctival grafting with fibrin glue C) Conjunctival biopsy showing actinic keratosis with squamous epithelial hyperplasia, hyperkeratosis and mild basal atypia. (Hematoxylin/ Eosin X100).

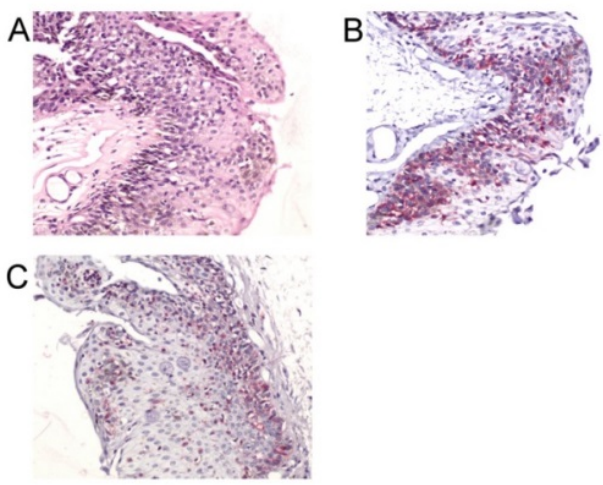

Figure 2: First conjunctival biopsy with atypical secondary acquired melanosis. A) Squamous epithelium manifesting atypical, predominantly basal, pigmented melanocytic proliferation (Hematoxylin/Eosin X200) B) Proliferating pigmented cells are positive with melanocyte marker HMB45 (X200) C) Proliferating pigmented cells are positive with melanocyte marker S100 (X200).

\section{Discussion}

The patient developed premalignant conjunctival lesions located at the 9 oclock and 3 oclock meridians of the eye which are sites that are least protected from UV radiation. This is known to be a predisposing factor in cutaneous malignancies. Histology of the first 2 lesions (right nasal limbal conjunctiva and left temporal limbal conjunctiva) showed actinic keratosis which is widely accepted as a precursor to squamous cell carcinoma. The first lesion was pigmented and also showed atypical melanosis. The third conjunctival lesion (right temporal conjunctiva) was removed after a delay of 7 months after discovery and histology showed conjunctival intraepithelial neoplasia 2 (CIN2). It is likely that the delay in removal resulted in the lesion progressing to CIN2.

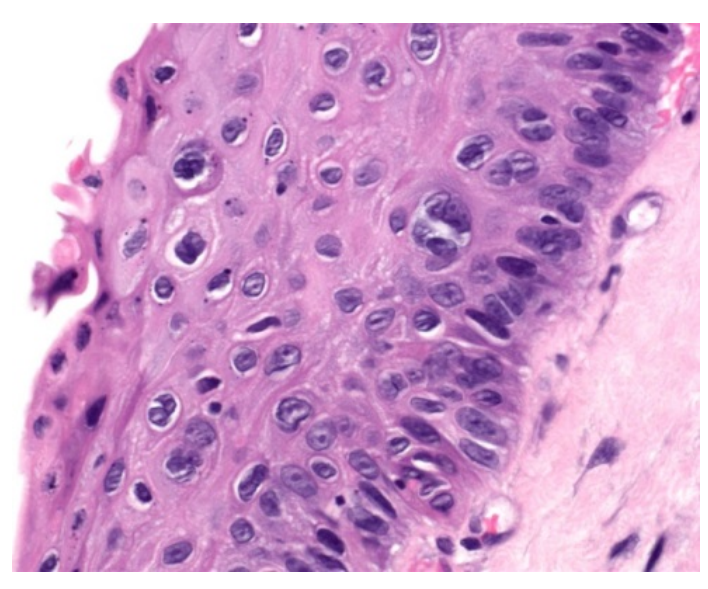

Figure 3: Third conjunctival biopsy with Conjunctival Intraepithelial Neoplasia, grade 2 (CIN2). Squamous epithelium is thickened and atypical cells predominate in lower two thirds. (Hematoxylin/Eosin X400).

Histopathologically, the first conjunctival biopsy showed hyperplastic squamous epithelium with hyperkeratosis and basal cell atypia in basal zone (Figure 1C) as well as atypical secondary acquired melanosis. The latter manifested as proliferation of mildly atypical pigmented cells predominantly in basal zone (Figure 2A). Proliferating cells showed expected reactions with melanocytic markers HMB45 and S100 (Figures 2B and 2C). The second conjunctival biopsy also showed actinic keratosis. The third conjunctival biopsy showed features of CIN2, namely atypical keratinocytes, predominating in lower two thirds of squamous epithelium (Figure 3).

\section{Conclusion}

We report a patient with xeroderma pigmentosum presenting with bilateral conjunctival premalignant lesions, actinic keratosis and CIN 2 in the right eye (temporal conjunctiva). The right eye nasal conjunctival lesion also showed an atypical secondary acquired melanosis which has not been previously reported.

\section{Acknowledgments}

The authors do not have any potential conflicts of interest, including relevant financial interests, activities, relationships, or affiliations to declare. We would like to acknowledge the Pathology Department of 
Citation: Lim EWL, Lim L, Jajeh IA , Jayasinghe LS (2016) Conjunctival Dysplasia and Atypical Secondary Acquired Melanosis in Xeroderma Pigmentosum. J Cytol Histol 7: 1000405. doi:10.4172/2157-7099.1000405

Page 3 of 3

Singapore General Hospital for providing financial support for the immunohistochemistry staining in the histology images.

\section{References}

1. Kraemer KH, DiGiovanna JJ (2014) Xeroderma pigmentosum.

2. Kanavi MR, Javadi MA, Yeganeh HRZ (2008) Corneal involvement in xeroderma pigmentosum; a histopathologic report. J Opthalmic Vis Res 3: 66-69.
3. Kraemer KH, Lee MM, Scotto J (1987) Xeroderma pigmentosum: cutaneous, ocular, and neurologic abnormalities in 830 published cases. Arch Dermatol 123: 241-250.

4. Paridaens ADA, McCartney ACE, Hungerford JL (1992) Premalignant melanosis of the conjunctiva and the cornea in xeroderma pigmentosum. Br J Opthalmol 76: 120-122. 